\title{
Nafion Titania Nanotubes Nanocomposite Electrolytes for High-Temperature Direct Methanol Fuel Cells
}

\author{
Nonhlanhla Precious Cele, ${ }^{1}$ Suprakas Sinha Ray, ${ }^{2}$ and Lucky Sikhwivhilu ${ }^{3}$ \\ ${ }^{1}$ Department of Electrical Engineering, Centre for Energy and Electric Power, Tshwane University of Technology, Staartelitelite Road, \\ Pretoria 0001, South Africa \\ ${ }^{2}$ DST/CSIR Nanotechnology Innovation Centre, National Centre for Nano-Structured Materials, Council for Scientific and \\ Industrial Research, 1-Meiring Naude Road, Brummeria, Pretoria 0001, South Africa \\ ${ }^{3}$ Advanced Materials Division, DST/Mintek Nanotechnology Innovation Centre, Mintek, Private Bag X3015, Randburg, Johannesburg \\ 2125, South Africa
}

Correspondence should be addressed to Nonhlanhla Precious Cele, nonhlanhla.cele@gmail.com

Received 10 November 2011; Revised 15 May 2012; Accepted 22 May 2012

Academic Editor: Mauro Coelho dos Santos

Copyright (C) 2012 Nonhlanhla Precious Cele et al. This is an open access article distributed under the Creative Commons Attribution License, which permits unrestricted use, distribution, and reproduction in any medium, provided the original work is properly cited.

\begin{abstract}
Nafion-based nanocomposite membranes containing various amounts of titania nanotubes (TNTs) as an inorganic filler have been prepared using melt-mixing method and have been investigated for proton exchange membrane applications. The onedimensional TNTs have been prepared from potassium hydroxide using hydrothermal route and conventional heating. Nafion $\mathrm{R} 1100$ in a protonated form was used, and TNT contents were in a range of $0.5-2.0 \mathrm{wt} \%$. The acid-treated composite membranes, at lowest inorganic additive content, exhibited improved properties in terms of thermal stability and methanol (MeOH) permeability. The best performing nanocomposite was the membrane containing only $0.5 \mathrm{wt} \%$ TNTs showing ionic conductivity value of $7.2 \times 10^{-2} \mathrm{~S} \cdot \mathrm{cm}^{-1}$ at $26^{\circ} \mathrm{C}$ and $100 \%$ of relative humidity.
\end{abstract}

\section{Introduction}

Currently, titanium dioxide $\left(\mathrm{TiO}_{2}\right)$ or titania-derived nanotubes (TNTs) are examined in respect with their possible prominent applications such as catalyst supports [1], photocatalyst [2], gas sensing elements [3], and anode materials for batteries [4]. Titanium-dioxide-supported noble metal catalysts, such as gold [5], silver, or platinum $[6,7]$, are effective in many important processes, such as selective oxidation and hydrogenation and automobile engine exhaust systems [8].

Principal advantages of the nanotubular form seem to be related to the property that they have high specific surface area, which allows diffusion of active species. The crystal structure of TNTs seems to be a derivative for many photocatalytic applications. Another property is that TNTs are often open at the end and accessible for the interaction with gaseous substances. The TNTs are also thermally stable up to $600^{\circ} \mathrm{C}$ [6-9]. These are some of the essential criteria for fuel cell electrolytes membranes. This promotes to study the Nafion/TNTs nanocomposite membranes behaviour with the aim to improve Nafion properties such as fuel permeability and thermal and mechanical stability.

Nafion, whose primary structure consists of acid tipped side chains dangling from a perfluorinated backbone, is expected to be compatible with TNTs, due to its reactive nature. The metal ions present in TNTs such as $\mathrm{K}^{+}$is expected to increase thermal stability of Nafion membrane. The resistance of TNTs in presence of $\mathrm{H}_{2}$ is likely to improve swelling and mechanical properties of Nafion membranes at higher temperatures greater than $100^{\circ} \mathrm{C}$. Therefore, to understand the effect of the interactions between Nafion and TNTs on the proton exchange membrane properties, further investigations were carried out. In this study, the effects of $\mathrm{TiO}_{2}$ nanotubes on Nafion properties such as water uptake, thermal stability, methanol $(\mathrm{MeOH})$ permeability, and ion conductivity were investigated. The nanocomposite membranes were prepared using melt-extrusion method by varying the nanofiller loadings. The mechanical, thermal properties, and ionic conductivity of membranes were 
investigated using dynamic mechanical analyser (DMA), thermogravimetric analyser (TGA), and electrochemical impedance spectroscopy (EIS). The vibration studies were carried out by FTIR spectroscopy, providing information on the nanofiller/Nafion, nanofiller/ $\mathrm{H}_{2} \mathrm{O}$, Nafion/ $\mathrm{H}_{2} \mathrm{O}$ interactions, and the conformation of fluorocarbon chains of Nafion hydrophobic domains. Methanol permeability was also investigated using the gas chromatography.

\section{Experimental Details}

2.1. Materials. Nafion precursor (R1100) was obtained from Ion Power. Potassium hydroxide $(\mathrm{KOH})$ and titanium dioxide powder was purchased from Merck chemicals and used as received.

2.2. Synthesis of $\mathrm{TiO}_{2}$ Nanotubes. $\mathrm{TiO}_{2}$-derived nanotubes (TNTs) were synthesized using a procedure described elsewhere [9-11]. In a typical procedure about $23 \mathrm{~g}$ of $\mathrm{TiO}_{2}$ powder, P25 Degussa, was mixed with $200 \mathrm{~mL}$ of $18 \mathrm{M}$ of aqueous solution of $\mathrm{KOH}$. The mixture was heated at $150^{\circ} \mathrm{C}$ in an autoclave with constant stirring for 24 hours. The product was then washed with deionized water and then dried in an oven at $120^{\circ} \mathrm{C}$ for 14 hours.

2.3. Membrane Preparation. The TNTs were used as filler during the preparation of polymer nanocomposite membranes. The nanocomposite membranes were prepared by melt-extrusion method using a microextruder Reomix OS (HAAKE) instrument. Nafion (R1100) and TNTs were meltmixed at $250^{\circ} \mathrm{C}$ at a rotor speed of $60 \mathrm{rpm}$ for $10 \mathrm{~min}$. The TNTs were added after 2 min of melting Nafion inside the extruder. For each nanocomposite, the amount of TNTs loaded was varied from 0.5 to $2.0 \mathrm{wt} \%$ to study the effect of TNTs loading on the properties of Nafion. The nanocomposites samples were then converted into sheets or films with a thickness of about $0.2 \mathrm{~mm}$ using a Carver laboratory press at $2 \mathrm{MPa}$ and $250^{\circ} \mathrm{C}$. The nanocomposites were then hydrolysed, to introduce cation exchange properties into the membranes. The nanocomposites were immersed in a mixture of $15 \mathrm{wt} \%$ potassium hydroxide, $50 \mathrm{wt} \%$ of deionized water, and $35 \mathrm{wt} \%$ of dimethyl-sulfoxide at $80^{\circ} \mathrm{C}$ for 2 hours. This was followed by the repeated immersion (three times) in a fresh $3 \mathrm{M}$ nitric acid $\left(\mathrm{HNO}_{3}\right)$ for $1 \mathrm{~h}$ to complete protonation process.

\subsection{Characterisation Techniques}

2.4.1. Scanning Electron Microscopy (SEM). Dry membranes were manually fractured after cooling in liquid nitrogen, to expose their cross section. The morphology of the fractured sample surfaces was analysed using SEM (LEO 1525), operating at an accelerating voltage of $3-10 \mathrm{kV}$.

2.4.2. The Fourier Transform Infrared. FTIR spectroscopy 800 from Perkin Elmer that was used to study the elementary composition of the nanocomposites studies were carried out from 500 to $4000 \mathrm{~cm}^{-1}$.
2.4.3. X-Ray Diffraction. XRD patterns were measured on a Phillips X'Pert diffractometer using secondary graphite monochromatic $\mathrm{CuK} \alpha$ radiation $(\lambda=1.54060 \AA)$ at $40 \mathrm{kV} / 50 \mathrm{~mA}$. Measurements were taken using angle of incidence detector at an angle of $2^{\circ}$, for $2 \theta$ values over 10 $70^{\circ}$ in steps of $0.05^{\circ}$.

2.4.4. The Thermogravimetric Analysis. TGA was conducted on a TGA Q500 (TA Instruments) at a heating rate of $10^{\circ} \mathrm{C} / \mathrm{min}$ in air, from room temperature to $800^{\circ} \mathrm{C}$.

Mechanical properties of pure Nafion and its TNTs containing composite membranes were studied by a Perkin Elmer DMA 8000 in the dual cantilever bending geometry. The temperature dependence of loss tangent $(\tan \delta$, loss modulus/storage modulus) of all samples were measured at a constant frequency of $1 \mathrm{~Hz}$ with the strain amplitude of $0.02 \%$ from room temperature to $180^{\circ} \mathrm{C}$ with a heating rate of $2^{\circ} \mathrm{C} / \mathrm{min}$.

2.4.5. Electrical Conductivity. The electrical resistivity was measured at room temperature using the four point collinear probe method. The equidistant tungsten carbide probes have a separation distance $(s)$ and probe radius of $0.127 \mathrm{~cm}$ and $0.005 \mathrm{~cm}$, respectively. The $1 \times 1 \mathrm{~cm}^{2}$ samples were prepared with a thickness of about $0.2 \mathrm{~cm}$. The Keithley 4200-SCS Semiconductor Characterisation System, equipped with four supply and measure units (SMUs) and an amplifier, was used to perform high-precision direct current characterisation by supplying currents ranging from $1 \mathrm{fA}$ to $1 \mathrm{~mA}$. The resistivity changes as a function of probe spacing $(0.127 \mathrm{~cm})$ and is given by:

$$
\rho=2 \pi s \frac{V}{I}, \quad \text { for } t \gg s,
$$

where $V$ is the measured voltage, $I$ is the supplied current, and $t$ is the thickness of the films $[10,12]$. The electrical conductivity is then given by

$$
\sigma=\frac{1}{\rho} .
$$

2.4.6. Electrochemical Impedance. Proton conductivity of fuel cell membrane was measured using a galvanostatic fourpoint probe AC electrochemical impedance spectroscopy (EIS) technique, which is relatively so insensitive to the contact impedance that it could be adequate to accurately test membranes with high conductivity. A standard electrochemical conductivity cell was used as a reference. The experimental data was fitted to the equivalent circuits and the electrolyte resistance $(R)$ was estimated from fitting procedure. The proton or ionic conductivity $(\sigma)$ is calculated by

$$
\sigma=\frac{d}{R l t},
$$

where $\sigma$ is the proton conductivity, $d$ is the distance between the electrodes and $R$ denotes the electrolyte resistance, respectively. $l$ and $t$ are the length and thickness of 

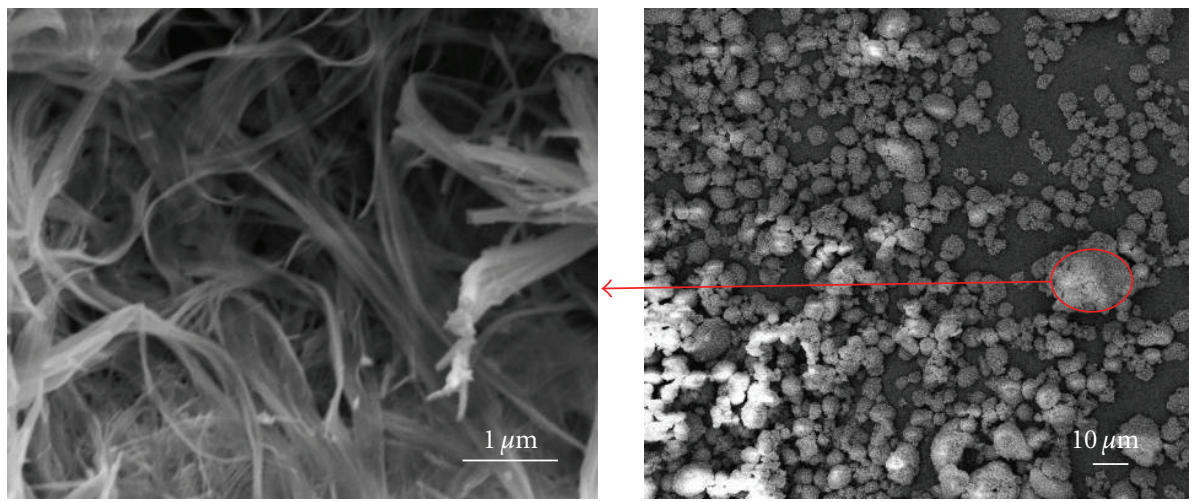

FIGURE 1: The SEM micrographs of titanium dioxide nanotubes synthesised using hydrothermal conventional heating method.

the membrane, respectively. The electrochemical cell was connected using a two-point probe technique to an Auto lab model 4.90006 potentiostat and Frequency Response Analyser (FRA). The home made cell was used with the electrode spacing of $1 \mathrm{~cm}$, and the $3 \times 3 \mathrm{~cm}^{2}$ membranes were used. The FRA electrochemical impedance software was used for the impedance measurements and analysis from $1 \mathrm{MHz}$ to $1 \mathrm{~Hz}$ with the AC voltage amplitude of $5 \mathrm{mV}$.

2.4.7. Liquid Uptake. The nanocomposites films were completely dried in vacuum at $100^{\circ} \mathrm{C}$ for 24 hours and weighed $\left(W_{\text {dry }}\right)$ and then placed in water/methanol (50/50) by volume solution at $25^{\circ} \mathrm{C}$ for $24 \mathrm{~h}$. The nanocomposites films were then wiped dry quickly with filter paper and weighed $\left(W_{\text {wet }}\right)$. The water/methanol uptake was then calculated as

$$
\text { Water/methanol uptake }(\%)=\frac{W_{\text {wet }}-W_{\text {dry }}}{W_{\text {dry }}} * 100 \text {. }
$$

A methanol diffusion homemade cell was used based on previous reports [13]. Compartment A was filled with methanol solution and compartment $\mathrm{B}$ was filled with the same volume of deionized water. The membrane was clamped between the two compartments, and these were kept under stirring conditions during the experiment to avoid any concentration build-up in the two compartments. Methanol concentration profiles were determined over a period of time at different operating temperatures. Samples were kept for about 30 min between compartments. The concentration of methanol was determined by gas chromatography (GC).

2.4.8. Methanol (MeOH) Permeability. The measurements were carried out using a testing device constructed in our laboratories. The polymer membranes with surface area of $3 \times 3 \mathrm{~cm}^{2}$ were inserted between vessels $\mathrm{A}$ and $\mathrm{B}$. A $250 \mathrm{~mL}$ solution of $\mathrm{MeOH}(2 \mathrm{M})$ was transferred to vessel A, whilst vessel B was filled with $250 \mathrm{~mL}$ of deionised water $\left(\mathrm{H}_{2} \mathrm{O}\right)$. After $24 \mathrm{~h}$, the amount of methanol that crossed through the membrane to vessel $\mathrm{B}$ was determined by gas chromatography (GC 17A, Shimadzu model). The gas chromatograph was equipped with a capillary column (14\% cyanopropyl phenyl methyl polysiloxane, $30 \mathrm{~m} \times$ $0.25 \mathrm{~mm} \times 1.0 \mu \mathrm{m})$ and a flame ionisation detector (FID).
The permeability of methanol through the membrane can be expressed with diffusion coefficient, $P\left(\mathrm{~cm}^{2} \cdot \mathrm{s}^{-1}\right)$ using equation (4) [14]

$$
P=\frac{k V L}{A \Delta C},
$$

where $k$ is the slope of the concentration profile $\left(\mathrm{mol} / \mathrm{cm}^{3} \cdot \mathrm{s}\right), V$ is the volume of a solution in compartment $\left(\mathrm{cm}^{3}\right), L$ is thickness of the membrane $(\mathrm{cm}), A$ is the active surface area of the membrane $\left(\mathrm{cm}^{2}\right)$, and $\Delta C$ is the difference of methanol concentration between two compartments $\left(\mathrm{mol} / \mathrm{cm}^{3}\right)$.

\section{Results and Discussions}

3.1. Structure and Morphology of Titania Nanotubes. The SEM results of the TNTs samples are shown in Figure 1. The samples show the tubular structures with diameter ranging from 10 to $20 \mathrm{~nm}$. Large bundles of TNTs structures agglomeration are observed (see low magnification). This is attributed to the presence of $\mathrm{K}^{+}$ions in the TNT structures, which can lead to an increase in the surface charge and electrostatic attraction between the tubes leading to agglomeration. This thermodynamic synthesis mechanism results in the formation of $\mathrm{KTiO}_{2}(\mathrm{OH})$ due to the presence of $\mathrm{K}^{+}$.

Figure 2(a) shows the FTIR spectra for TNTs that have been annealed at $300^{\circ} \mathrm{C}$. The peaks corresponding to physically adsorbed water $(\mathrm{O}-\mathrm{H}$ stretching mode at $\sim 3400$ $\mathrm{cm}^{-1}$ and $\mathrm{O}-\mathrm{H}$ bending mode at $\sim 1640 \mathrm{~cm}^{-1}$ ) all disappeared due to the higher annealing temperature of $300^{\circ} \mathrm{C}$. This is consistent with the literature [15]. Only the Ti-O stretching mode is observed at $-640 \mathrm{~cm}^{-1}$ and $400 \mathrm{~cm}^{-1}$; this is attributed to the amorphous and anatase phase of TNT. XRD patterns for TNTs are shown in Figure 2(b) revealed the presence of both anatase and rutile phase. The additional peaks are ascribed to the interaction of $\mathrm{K}^{+}$ions and $\mathrm{TiO}_{2}$ and have been previously reported $[10,15]$.

3.2. Structural Properties of Nanocomposite Membranes. The FTIR spectra showing vibration bands of Nafion and Nafion/TNTs nanocomposites are shown in Figure 3. The bands around $1200-620 \mathrm{~cm}^{-1}$ denote $\mathrm{CF}_{2}-\mathrm{CF}_{2}$ stretching, and the bands around $1050 \mathrm{~cm}^{-1}$ denote the- $\mathrm{SO}_{3}$-symmetric 


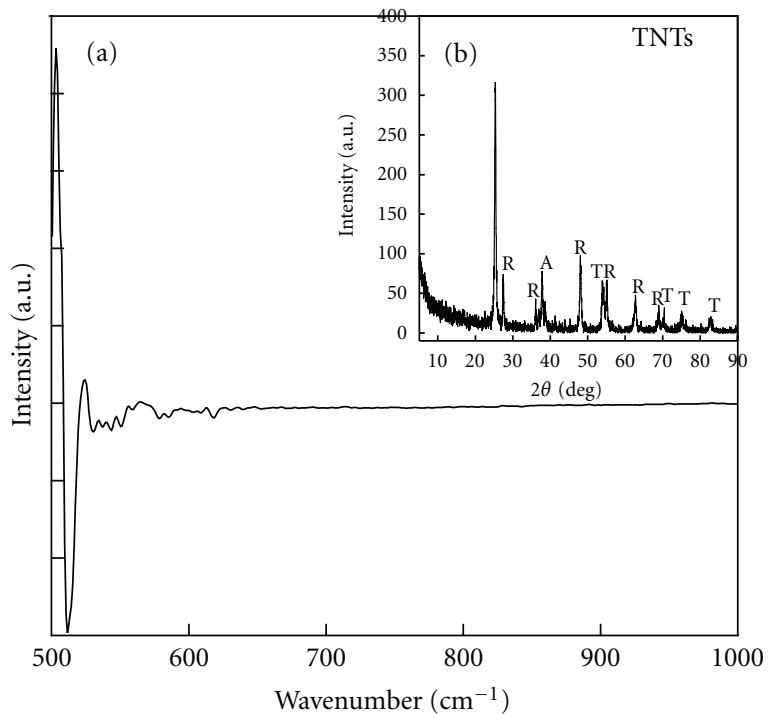

FIGURE 2: (a) FTIR spectra of TNTs and (b) XRD patterns of TNTs synthesised using hydrothermal conventional heating method and annealed at $300^{\circ}$.

stretching. All these bands are characteristics of the Nafion membrane [14, 16-18]. The vibration bands of Nafion and nanocomposite membranes are similar; this might be due to the very small amount of TNTs loading or poor interaction with polymer matrix.

3.3. Morphology. The SEM investigation was performed on the nanocomposite membranes, and micrographs are shown Figure 4. Samples were frozen and fractured to expose the cross-sectional surface of the nanocomposite membranes containing various amounts of TNTs in wt $\%$ 4(a) $0.5,4$ (b) 1.0, and 4(c) 2.0. The micrographs show the presence of inorganic structures, homogeneously dispersed into polymer matrix. This indicates the presence of bundle TNTs into Nafion matrix. SEM images show similar dispersion for all TNTs loadings. This is in agreement with XRD results, demonstrating that TNTs nanocomposite had the same dspacing independent of TNTs loadings. This good dispersion suggests that the number of accessible sites on the surface of TNTs is high contributing to the adhesion and electrostatic interaction.

3.4. Water/Methanol Uptake and Electrical Conductivity. The hydration of the Nafion membranes is crucial to maintain higher proton conductivity. However, the methanol or fuel crossover must be reduced to avoid the catalyst poising and improve the fuel cell performance. The water/methanol uptake was analysed to maintain higher fuel cell performance. The water uptake increases from $19 \%$ for pure Nafion to a maximum of about $22 \%$ for $1.0 \mathrm{wt} \%$ TNTs composite as shown in Figure 5. The water uptake of N-0.5 wt $\%$ TNTs and N-2 wt $\%$ TNTs remains at about $20 \%$. The increase in water uptake with addition of TNTs suggests an increase in hydrophilic nature of Nafion.

The bulk electrical conductivity of Nafion and its TNTsbased nanocomposite membranes is shown in Figure 5.

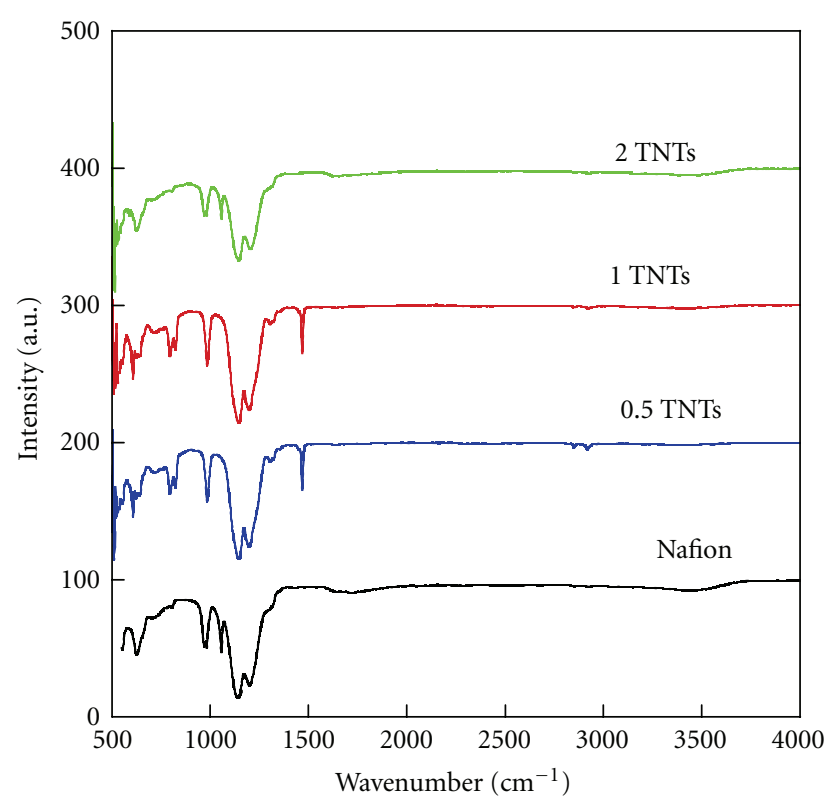

FIGURE 3: FTIR spectra of Nafion and its TNTs-based nanocomposite membranes with different TNTs loadings in wt $\%$ taken from 500 to $4000 \mathrm{~cm}^{-1}$.

The electrical conductivity of Nafion increases from 0 to $0.06 \mathrm{~S} \cdot \mathrm{cm}^{-1}$, when modified with $0.5 \mathrm{wt} \%$ of TNTs; it further increases to about $0.08 \mathrm{~S} \cdot \mathrm{cm}^{-1}$, with $1.0 \mathrm{wt} \%$ incorporation. As the amount of TNTs into Nafion matrix increases to $2 \mathrm{wt} \%$, the electrical conductivity decreases to zero, which is the same as that of pure Nafion. This decrease is associated with the electrical percolation threshold of Nafion and also the poor interaction between Nafion and TNTs as observed in FTIR spectra for $2 \mathrm{wt} \%$.

3.5. Thermal Stability. Thermogravimetric analyses (TGA) of Nafion and its TNTs-based nanocomposite membranes are shown in Figure 6. Thermal degradation profiles of the nanocomposite samples are similar and show that the membranes are more thermally stable up to about $400^{\circ} \mathrm{C}$ compared to Nafion. The first degradation stage in a range of $30-120^{\circ} \mathrm{C}$ is assigned to the decomposition of physically adsorbed water present in the membranes. The weight loss in the range of $250-400^{\circ} \mathrm{C}$ is associated with the degradation of $-\mathrm{SO}_{3} \mathrm{H}$-groups of Nafion [17]. This increase in thermal stability is attributed to the presence of $\mathrm{TiO}_{2}$ nanostructures into Nafion. The results show a slightly higher thermal stability for $0.5 \mathrm{wt} \%$ of TNTs. This is attributed to the good interaction between Nafion matrix, which is in agreement with the SEM results.

3.6. Proton Conductivity and Methanol (MeOH) Permeability. To evaluate the influence of TNTs on the membranes electrochemical behaviour, electrochemical impedance spectroscopy measurements were performed. Figure 7 shows a Nyquist plot of Nafion and TNTs-based nanocomposites at $100 \%$ relative humidity. The plot gives electrolytes resistance $(R)$ of the materials. The nanocomposite containing $0.5 \mathrm{wt} \%$ TNTs has the lowest $R=210 \Omega$ (see Table 1). The electrolyte 


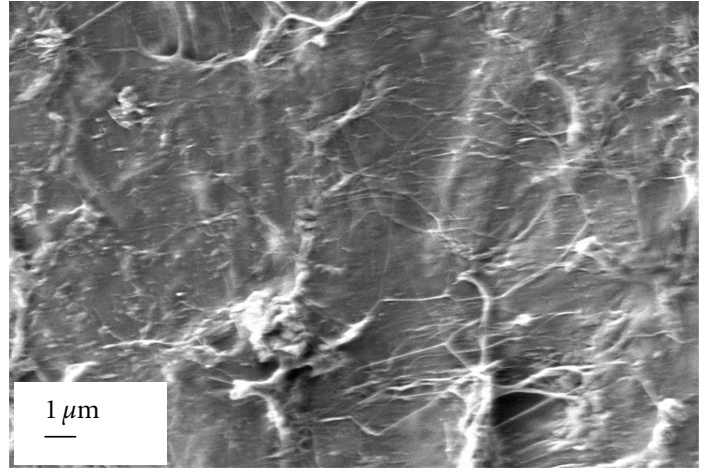

(a)

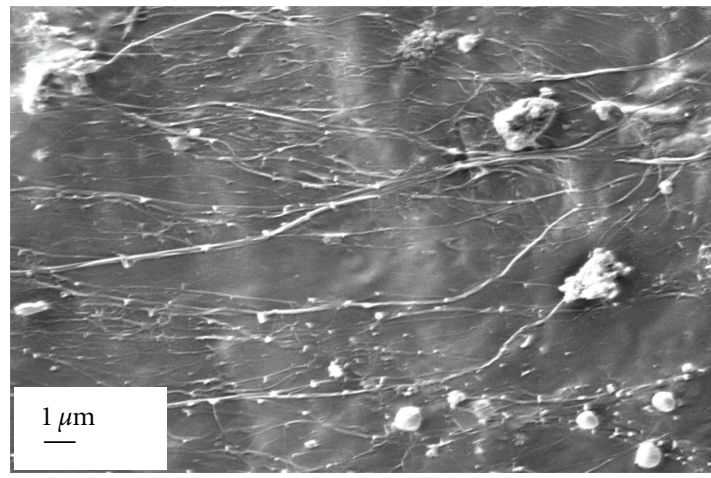

(b)

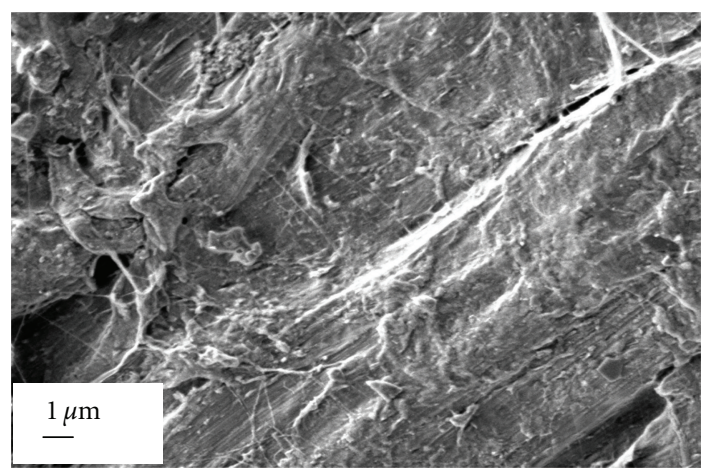

(c)

Figure 4: The SEM micrographs of the nanocomposite membranes containing various amounts of TNTs in wt $\%$ (a) 0.5 , (b) 1.0 , and (c) 2.0.

resistance increases as the TNTs loading increases to 1.0 and $2.0 \mathrm{wt} \%$. This is indicative of a decrease in proton conductivity. This suggests that the amount of TNTs strongly influence the proton conductivity of Nafion. This decrease in proton conductivity can be due to the TNTs structures hindering the permeability of hydrogen ions. Whereas the electrolytes resistance decreases when $0.5 \mathrm{wt} \%$ TNTs was incorporated, indicating an increase in proton conductivity compared to pure Nafion. This increase in proton conductivity is related to the increase in water uptake observed with $1 \mathrm{wt} \%$ TNTs nanocomposite. The $\mathrm{MeOH}$ permeability was increased to $3 \times 10^{-8} \mathrm{~cm}^{2} \cdot \mathrm{s}^{-1}$ with $1.0 \mathrm{wt} \%$ TNTs nanocomposite and sharply decreases to $1 \times 10^{-8} \mathrm{~m}^{2} \cdot \mathrm{s}^{-1}$ as the amount of TNTs increases to $2 \mathrm{wt} \%$. This behaviour is due to the

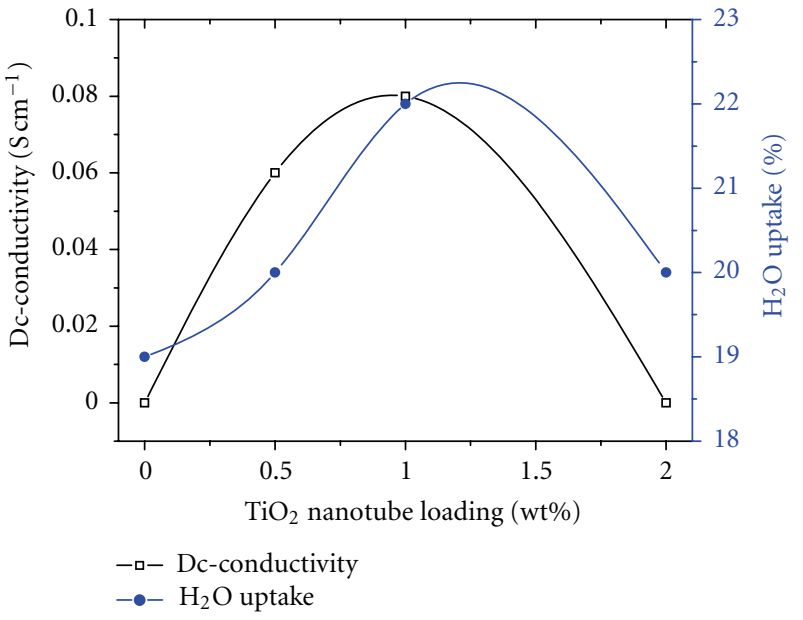

FIgURE 5: The bulk electrical conductivity and water-uptake plots of Nafion, and its TNTs-based nanocomposite membranes containing various amounts of TNTs.

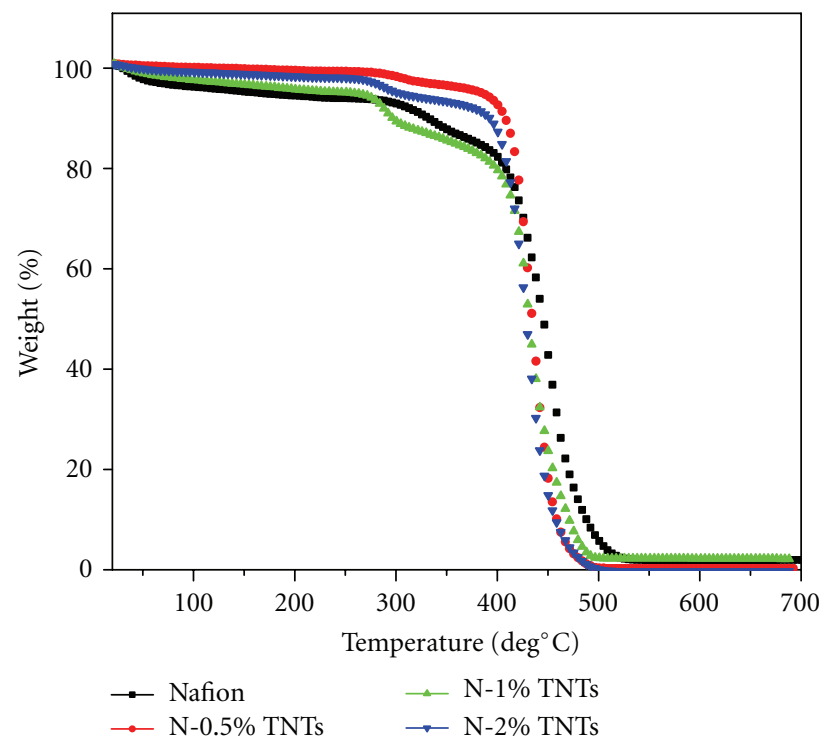

Figure 6: TGA plot of Nafion and TNTs-based nanocomposite membranes, with different loadings measured in nitrogen at $5^{\circ} \mathrm{C}$ per min.

$\mathrm{MeOH}$ permeability percolation threshold, which is affected by TNTs dispersed in Nafion.

The ratio of proton conductivity $(\sigma)$ and methanol permeability $(P)$ was calculated in order to estimate the performance of these nanocomposite membranes in fuel cell applications. The calculated values of proton conductivity and $\mathrm{MeOH}$ permeability are shown in Table 1. A decrease in the ratio was observed with an incorporation of TNTs in difference proportions.

\section{Conclusion}

In this paper, TNTs-based Nafion nanocomposite membranes were prepared in different proportions by melt-extrusion method. Water uptake of nanocomposite 


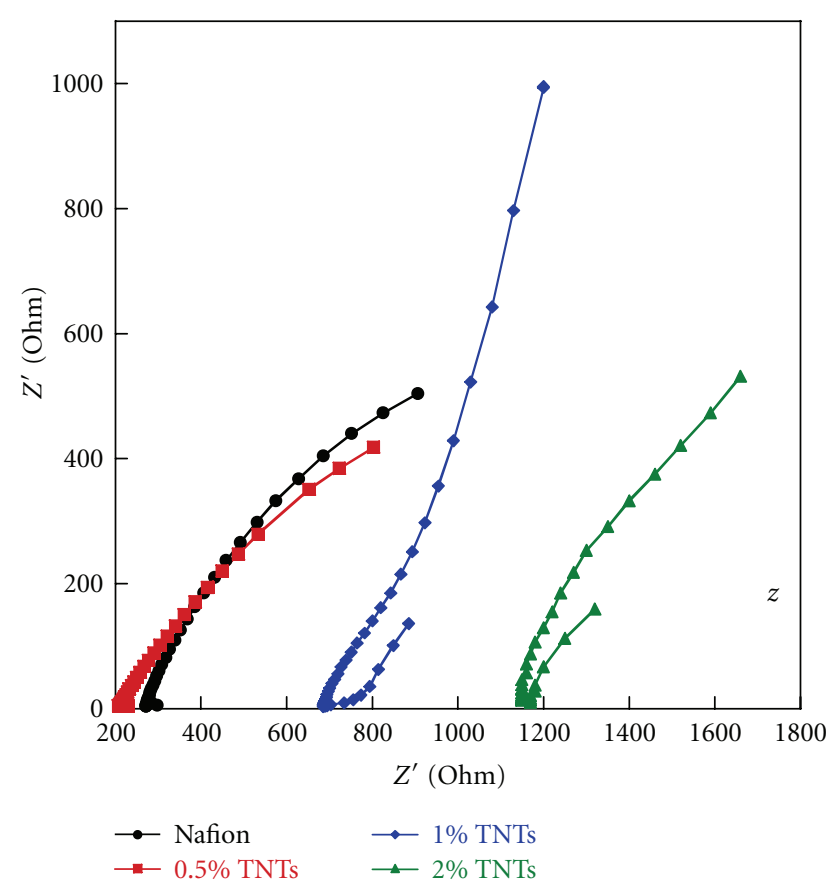

Figure 7: Nyquist plots of Nafion and its TNTs-based nanocomposite membranes, with different TNTs loadings ranging from 0.5 to $2.0 \mathrm{wt} \%$, measurements done at room temperature $\left(26^{\circ} \mathrm{C}\right)$ and $100 \%$ relative humidity.

TABle 1: Parameters for circuit elements evaluated by fitting data to the equivalent circuit and calculated conductivity for prepared composite membranes. The average calculated error is about $8 \%$.

\begin{tabular}{lccccc}
\hline Samples & $\begin{array}{c}t^{\mathrm{a}} \\
(\mathrm{cm})\end{array}$ & $\begin{array}{c}R^{\mathrm{b}} \\
(\Omega)\end{array}$ & $\begin{array}{c}\sigma^{\mathrm{c}} \\
(\mathrm{S} / \mathrm{cm})\end{array}$ & $\begin{array}{c}P^{\mathrm{d}} \\
\left(\mathrm{cm}^{2} \cdot \mathrm{s}^{-1}\right)\end{array}$ & $\begin{array}{c}(\sigma / P)^{\mathrm{e}} \\
\left(\mathrm{s} \cdot \mathrm{S} \cdot \mathrm{cm}^{3}\right)\end{array}$ \\
\hline Nafion & 0.020 & 230 & 0.070 & $2 \times 10^{-8}$ & $3.5 \times 10^{6}$ \\
N-0.5 wt\% TNTs & 0.022 & 210 & 0.072 & $2 \times 10^{-8}$ & $3.6 \times 10^{6}$ \\
N-1.0 wt\% TNTs & 0.022 & 690 & 0.022 & $3 \times 10^{-8}$ & $7.0 \times 10^{5}$ \\
N-2.0 wt\% TNTs & 0.021 & 1150 & 0.014 & $1 \times 10^{-8}$ & $1.0 \times 10^{6}$ \\
\hline
\end{tabular}

${ }^{\mathrm{a}}$ Thickness of the membrane, ${ }^{\mathrm{b}}$ electrolyte resistance, ${ }^{\mathrm{c}}$ proton conductivity, ${ }^{d}$ methanol permeability of nanocomposite membranes, ${ }^{\mathrm{e}}$ ratio of proton conductivity and water/MeOH uptake measurements.

membranes resulted higher than that of pure Nafion, with $\mathrm{N}-1.0 \mathrm{wt} \%$ TNTs reaching maximum of $21.5 \%$. The highest electrical conductivity was observed with $1.0 \mathrm{wt} \%$ TNTs nanocomposite but remains at zero with $2.0 \mathrm{wt} \%$ TNTs nanocomposite. The thermal stability of Nafion increases with incorporation of TNTs. A reduced $\mathrm{MeOH}$ permeability was observed with $2.0 \mathrm{wt} \%$ TNTs nanocomposite membrane. The proton conductivity of Nafion slightly increases when $0.5 \mathrm{wt} \%$ TNTs and then decreases with an increase in the amount of TNTs. The best performing nanocomposite was the membrane containing only $0.5 \mathrm{wt} \%$ TNTs showing ionic conductivity value of $7.2 \times 10^{-2} \mathrm{~S} \cdot \mathrm{cm}^{-1}$ at $26^{\circ} \mathrm{C}$ and $100 \%$ of relative humidity.

\section{Acknowledgments}

The authors would like to thank the Department of Science and Technology (RSA), the Council for Scientific and
Industrial Research (CSIR), and the Tshwane University of Technology for financial support.

\section{References}

[1] J. Z. Xu, W. B. Zhao, J. J. Zhu, G. X. Li, and H. Y. Chen, "Fabricating gold nanoparticle-oxide nanotube composite materials by a self-assembly method," Journal of Colloid and Interface Science, vol. 290, no. 2, pp. 450-454, 2005.

[2] I. Paramasivam, J. M. Macak, and P. Schmuki, "Fabrication of titania nanomaterial and study characters of dye-sensitized solar cells: from one-dimension to silver surface modification of $\mathrm{TiO}_{2}$," Electrochemistry Communications, vol. 10, no. 20, pp. 71-75, 2008.

[3] S. K. Hazra and S. Basu, "High sensitivity and fast response hydrogen sensors based on electrochemically etched porous titania thin films," Sensors and Actuators B, vol. 115, no. 1, pp. 403-411, 2006.

[4] J. Xu, C. Jia, B. Cao, and W. F. Zhang, "Electrochemical properties of anatase $\mathrm{TiO}_{2}$ nanotubes as an anode material for lithium-ion batteries," Electrochimica Acta, vol. 52, no. 28, pp. 8044-8047, 2007.

[5] L. Armelao, D. Barreca, G. Bottaro et al., "Recent trends on nanocomposites based on $\mathrm{Cu}, \mathrm{Ag}$ and $\mathrm{Au}$ clusters: a closer look," Coordination Chemistry Reviews, vol. 250, no. 11-12, pp. 1294-1314, 2006.

[6] G. M. Nuñez, R. J. Fenoglio, and D. E. Resasco, "Enhanced methane production from methanol decomposition over $\mathrm{Pt} / \mathrm{TiO}_{2}$ catalysts," Reaction Kinetics and Catalysis Letters, vol. 40, no. 1, pp. 89-94, 1989.

[7] S. C. Chan and M. A. Barteau, "Preparation of highly uniform $\mathrm{Ag} / \mathrm{TiO}_{2}$ and $\mathrm{Au} / \mathrm{TiO}_{2}$ supported nanoparticle catalysts by photodeposition," Langmuir, vol. 21, no. 12, pp. 5588-5595, 2005.

[8] Y. Ishibai, J. Sato, S. Akita, T. Nishikawa, and S. Miyagishi, "Photocatalytic oxidation of $\mathrm{NOx}$ by Pt-modified $\mathrm{TiO}_{2}$ under visible light irradiation," Journal of Photochemistry and Photobiology A, vol. 188, no. 1, pp. 106-111, 2007.

[9] M. M. Souza, N. F. Ribeiro, and M. Schmal, "SOFC using pure hydrogen considering air back diffusion phenomenon," International Journal of Hydrogen Energy, vol. 32, no. 2, pp. 423-425, 2007.

[10] L. M. Sikhwivhilu, S. Sinha Ray, and N. J. Coville, "Influence of bases on hydrothermal synthesis of titanate nanostructures," Applied Physics A, vol. 94, no. 4, pp. 963-973, 2009.

[11] T. Kasuga, M. Hiramatsu, A. Hoson, T. Sekino, and K. Niihara, "Formation of titanium oxide nanotube," Langmuir, vol. 14, no. 12, pp. 3160-3163, 1998.

[12] S. Pavlidou and C. D. Papaspyrides, "A review on polymerlayered silicate nanocomposites," Progress in Polymer Science, vol. 33, no. 12, pp. 1119-1198, 2008.

[13] N. P. Cele, S. Sinha Ray, S. K. Pillai et al., "Carbon nanotubes based nafion compositemembranes for fuel cell applications," Fuel Cells, vol. 10, no. 1, pp. 64-71, 2010.

[14] S. Quezabo, J. C. T. Kwak, and M. Falk, "An infrared study of water-ion interactions in perfluorosulfonate (Nafion) membranes," Canadian Journal of Chemistry, vol. 62, no. 1, pp. 958-966, 1984.

[15] U. Jeong and Y. Xia, "Synthesis and crystallization of monodisperse spherical colloids of amorphous selenium," Advanced Materials, vol. 17, no. 1, pp. 102-106, 2005.

[16] M. Falk, "An infrared study of water in perfluorosulfonate (Nafion) membranes," Canadian Journal of Chemistry, vol. 58, no. 1, pp. 1496-1501, 1980. 
[17] H. L. Yeager and A. Steck, "Cation and water diffusion in nafion ion exchange membranes: influence of polymer structure," Journal of the Electrochemical Society, vol. 128, no. 9, pp. 1880-1884, 1981.

[18] Xie, Q. Zhuang, Q. Wang, X. Liu, Y. Chen, and Z. Han, "In situ synthesis and characterization of $\operatorname{poly}(2,5$-benzoxazole)/ multiwalled carbon nanotubes composites," Polymer, vol. 52, no. 1, pp. 5271-5276, 2011. 

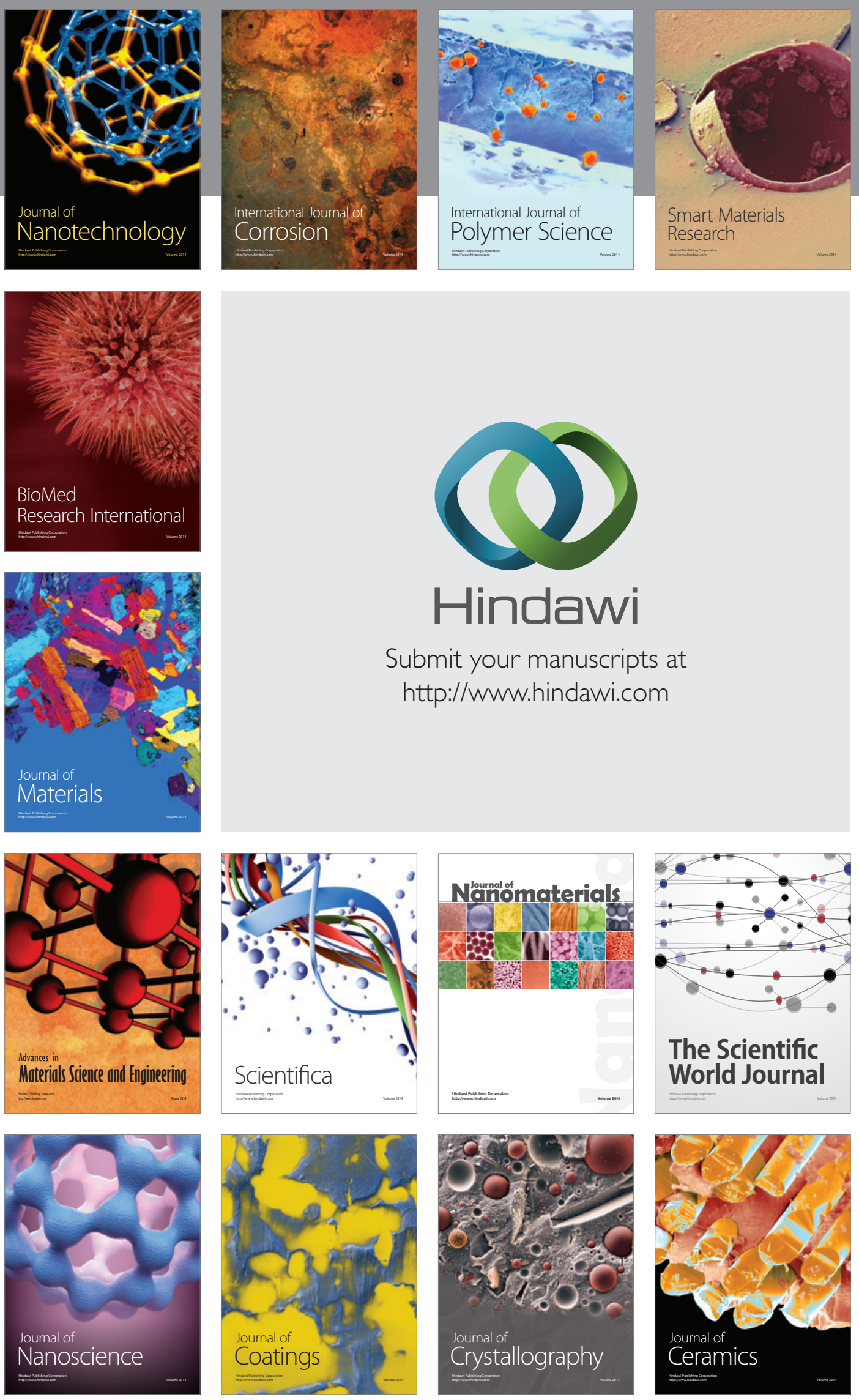

The Scientific World Journal

Submit your manuscripts at

http://www.hindawi.com

\section{World Journal}

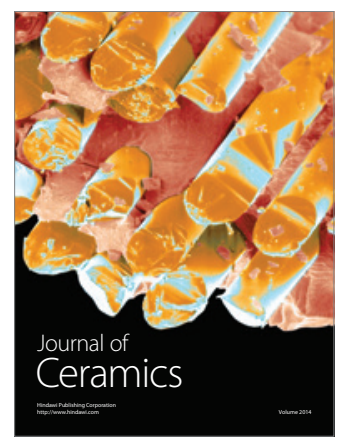

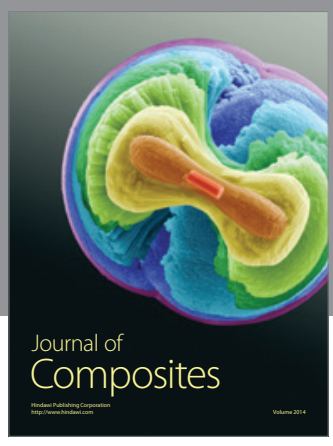
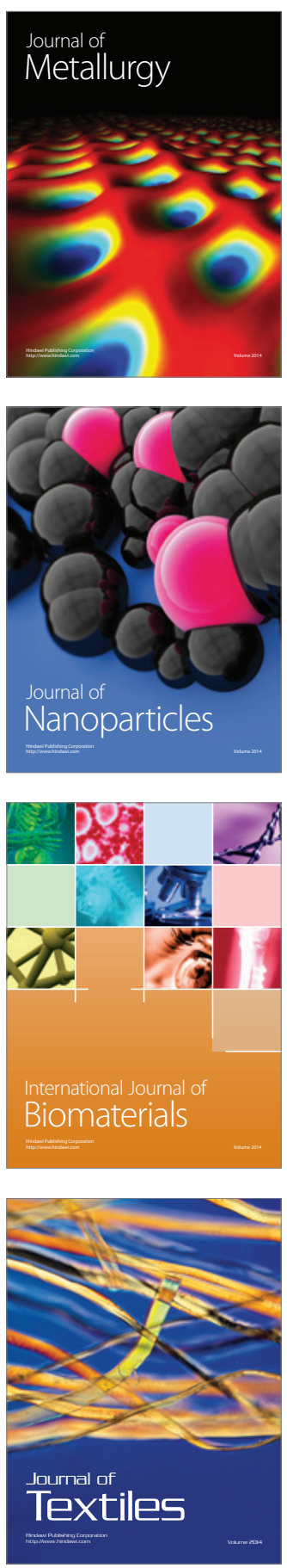